\title{
Power System Transient Stability Analysis With SSSC Controller
}

\author{
P.Nagaraju Mandadi ${ }^{1}$ and Dr. K.Dhanvanthri ${ }^{2}$ \\ ${ }^{1}$ CVR College of Engineering, Department of EEE., Ibrahimpatan, R.R.District, A.P., India \\ Email: mandadi.nagaraju@gmail.com \\ ${ }^{2}$ CVR College of Engineering, Department of EEE., Ibrahimpatan, R.R.District, A.P., India \\ E-mail: kdhanvanthri@gmail.com
}

\begin{abstract}
The SSSC FACTS controller is applied to a multi--machines power system for analysis of Transient stability during faults under different fault clearing times using MATLAB / SIMULINK setups developed in this work. The developed SIMULINK setup is a very general approach showing clearly the effects of change of any parameter on the Transient stability of a power system. The oscillations in the power system has been shown to get damped out very effectively by SSSC controller and in this method of analysis, it has been shown that a desired Transient response can be obtained very easily and quickly with the use of the developed SIMULINK setup on any power system .
\end{abstract}

Index Terms--SSSC, damping, Transient stability, Simulink, MATLAB and FACTS.

Nomenclature:

$\delta$-Generator rotor angle

$\omega$ - Generator rotor speed

E - Magnitude of the internal voltage

$\mathrm{V}$-Infinite bus voltage

$\mathrm{H}$-Inertia constant in Sec

$\mathrm{X}_{\mathrm{d}}{ }^{1}$-Generator transient reactance

$\mathrm{X}_{\mathrm{L}}$ - Line reactance

$\mathrm{P}_{\mathrm{e}}$ - Electrical power output in p.u

$P_{m}$ - Mechanical power input in p.u

$\mathrm{V}_{\mathrm{S}}$ - Controllable voltage provided by SSSC.

$\theta$ - Angle of line current.

$\alpha_{\mathrm{S}}$-Angle of SSSC voltage.

$\mathrm{Y}_{\mathrm{b}} \mathrm{f}$-Reduced system Admittance value before fault.

$\mathrm{Y}_{\mathrm{d} f}$-Reduced system admittance value during fault.

$\mathrm{Y}_{\mathrm{af}}$-Reduced system admittance value after fault clearance.

\section{INTRODUCTION}

One of the major problems in power system has been its stability which is defined as its ability to supply electrical power under disturbances. If the disturbance is small, it is known as 'steady state stability' whereas if it is large and sudden, it is called 'Transient
Stability'. In addition to this, if there occurs a fault, it is more involved because there will be network changes during and after fault clearance. In Transient stability analysis, the total system is reduced to only the number of generators and the electrical powers from each of the generators are calculated both during and after the fault clearance ${ }^{1}$.

The Transient stability can be determined solving the non-linear swing equation using any of the available numerical methods using MATLAB. In this process, SIMULINK setup is used which is accurate, fast, easy and reliable. Also the effects of variation of any of the system parameters can be quickly obtained either in terms of numerical values or in terms of Graphs. These graphs can be easily obtained using the facilities available in MATLAB. Because of the above mentioned advantages, SIMULINK setup only is used for the entire analysis of the problem involved in this work.

During Transient stability problem, it is a fact that the system is subjected to oscillations and these have to be damped within a given time. To achieve damping, 'Power System Stabilizers' are used but to get the required effect from this, it is essential that it has to be designed properly. The development of recent FACTS(Flexible AC Transmission System) devices such as STATCOM, SVC, TCSC,SSSC(Static Synchronous Series Compensator) etc are being used for getting fast and effective control for damping mechanical oscillations. ${ }^{2}$

This paper analyzes Transient stability of Multi-Machine Power System. The MultiMachine power system considered in this paper is the standard 3 Machine 9 Bus System $^{1}$ considering fault and its clearance and the effect of SSSC is observed using the developed Simulink setup. The method suggested and the Simulink link setups developed can be applied to any power system. This is mainly because of the accuracy and correctness of the Simulink setups. 


\section{ANALYSIS OF SSSC (STATIC SYNCHRONOUS SERIES COMPENSATOR):}

The SSSC is a solid-state voltage source inverter connected in series to power transmission lines ${ }^{3}$. It can vary the effective impedance of a transmission line such that it can influence the power flow by injecting a controllable voltage $\mathrm{V}_{\mathrm{S}}$. This injected voltage will be in quadrature with the line current and emulates an Inductive or Capacitive reactance. For the SSSC, the only controllable parameter is the magnitude of $\mathrm{V}_{\mathrm{S}}$. It is also to be mentioned that $\mathrm{V}_{\mathrm{S}}$ changes only the current magnitude and not its angle.

In the case of SSSC, the current is given by

$$
\bar{I}_{\mathrm{s}}=\frac{\bar{E}-\overline{V_{S}}-\bar{V}}{j X}
$$

$\overline{V_{S}}$ is kept in quadrature with the line current and is given as

$$
\overline{V_{S}}=\mathbf{V}_{\mathbf{S}} e^{j \alpha_{S}}
$$

When $\mathrm{V}_{\mathrm{S}}$ lags the line current by $90^{\circ}$, the SSSC behaves like a capacitive reactance.

The angle $\theta$ can be expressed as

$$
\theta=\tan ^{-1}\left(\frac{V-E \cos \delta}{E \sin \delta}\right)
$$

The electrical power is given by

$$
\mathbf{P}_{\mathrm{e}}=\frac{E V}{X} \sin \delta+\frac{V V_{S}}{X} \cos \theta
$$

The term $\cos \theta$ is given by

$$
\frac{E \sin \delta}{\sqrt{E^{2}+V^{2}-2 E V \cos \delta}}
$$

Equation (1) combined with above and $\mathrm{P}_{\mathrm{e}}$ can be written as

$$
\mathbf{P}_{\mathrm{e}}=\left(\frac{E V}{X} \sin \delta\right)(1+\xi)
$$

Where

$$
\xi=\frac{V_{S}}{\sqrt{E^{2}+V^{2}-2 E V \cos \delta}}
$$

Rotor speed deviation $\omega$ is taken as control signal. $\mathrm{V}_{\mathrm{S}}$ is dynamically related to $\omega$ and must satisfy

$$
\begin{gathered}
\mathrm{V}_{\mathrm{S}}=\mathrm{k}_{1} \omega ; \\
-\mathrm{V}_{\mathrm{S} \max } \leq V_{S} \leq V_{S \max }
\end{gathered}
$$

and $\mathrm{k}_{1}$ is a positive gain.

\section{POWER SYSTEMS CONSIDERED FOR ANALYSIS.}

The concepts developed with regards to SSSC controller is applied to the standard (Western System Coordinated Council) WSCC 3 Machine 9 Bus system ${ }^{1}$ as shown in Figure 1.

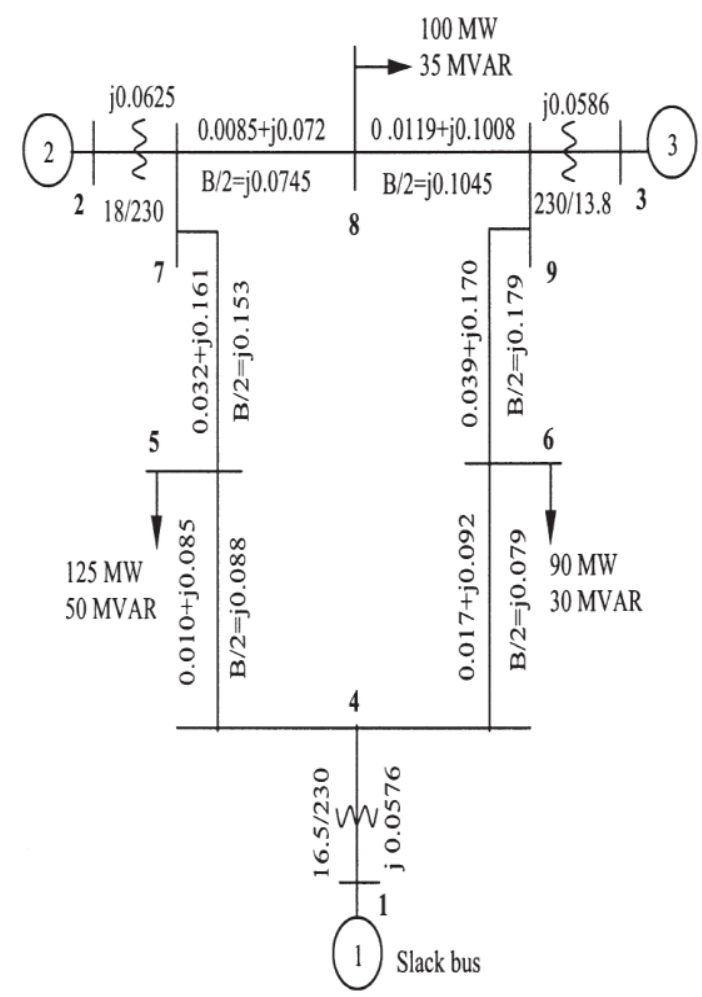

Figure 1. WSCC 3-Machine, 9 Bus System: All Impedances are in P.U on a 100 MVA base

The SIMULINK setup for analyzing WSCC 3 Machine 9 BUS system with fault and without SSSC controller is given in Figure 2. 


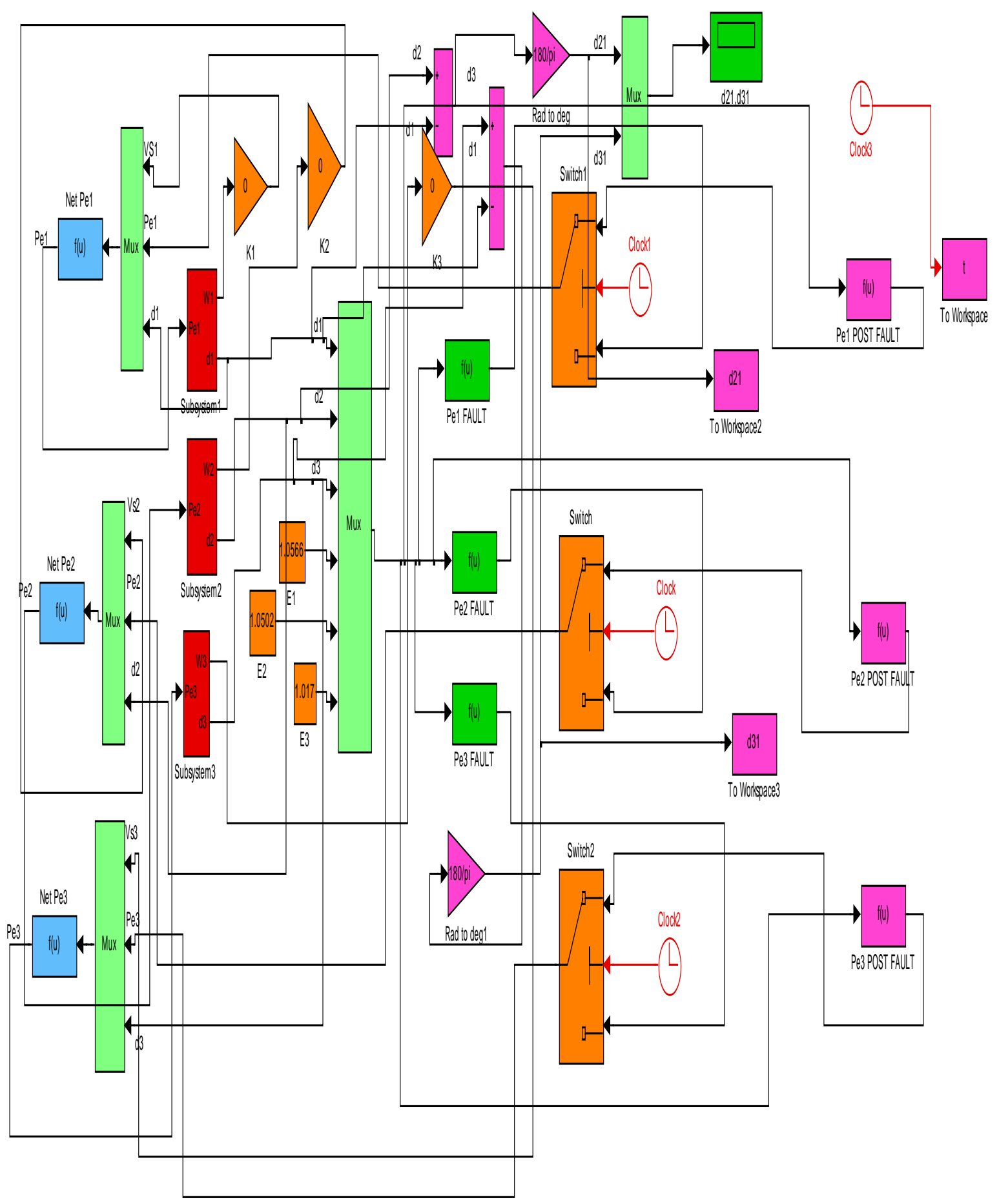

Figure 2. Transient Stability Analysis of 9 Bus, 3 M/C Power System Analysis without SSSC Controller, Fault at Bus 6, Line 6-9 removed. 
The swing curve with fault and without SSSC is shown in Figure 3.

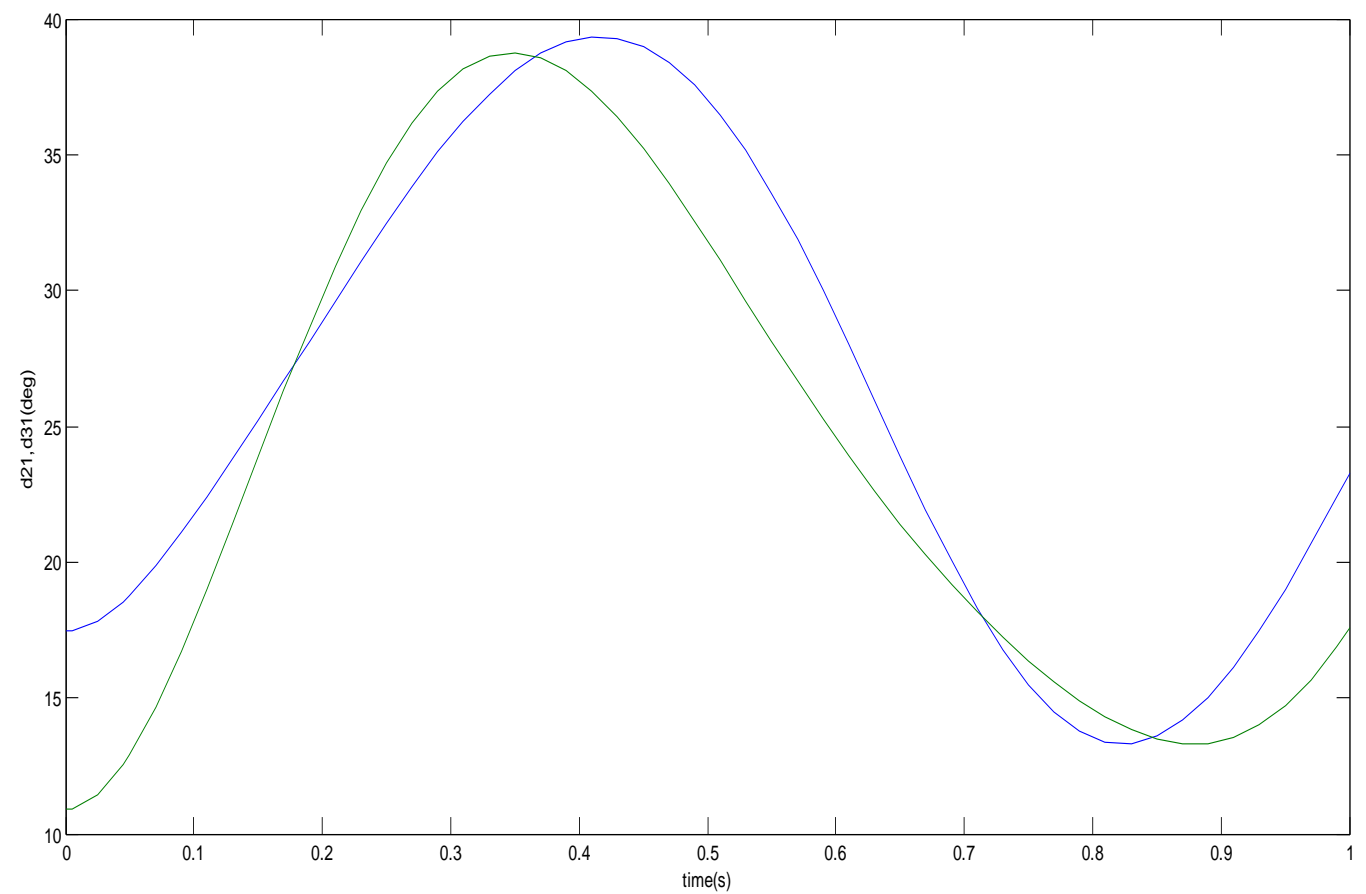

Figure 3.

The Simulink setup with SSSC controller is shown in Figure 4.

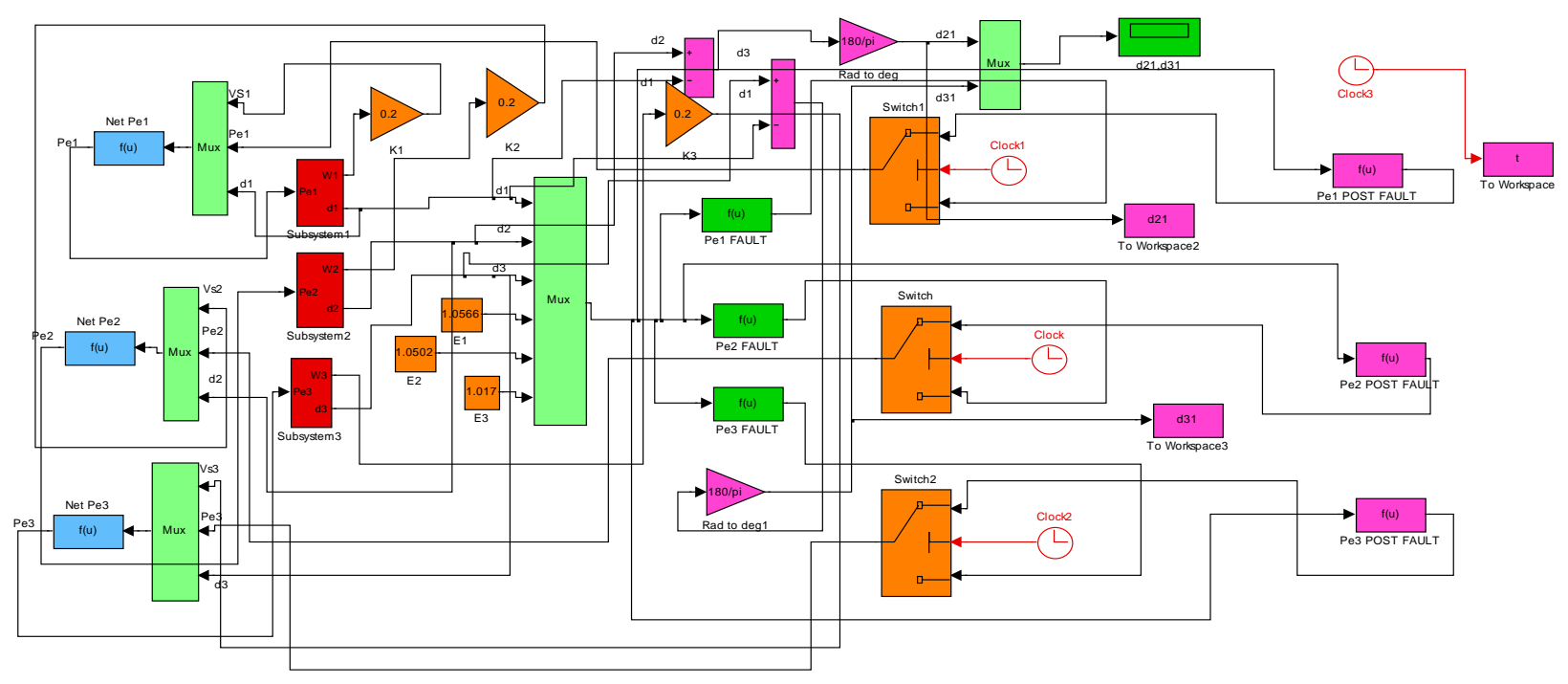

Figure 4. 
The swing curve with fault and with SSSC controller is shown below.

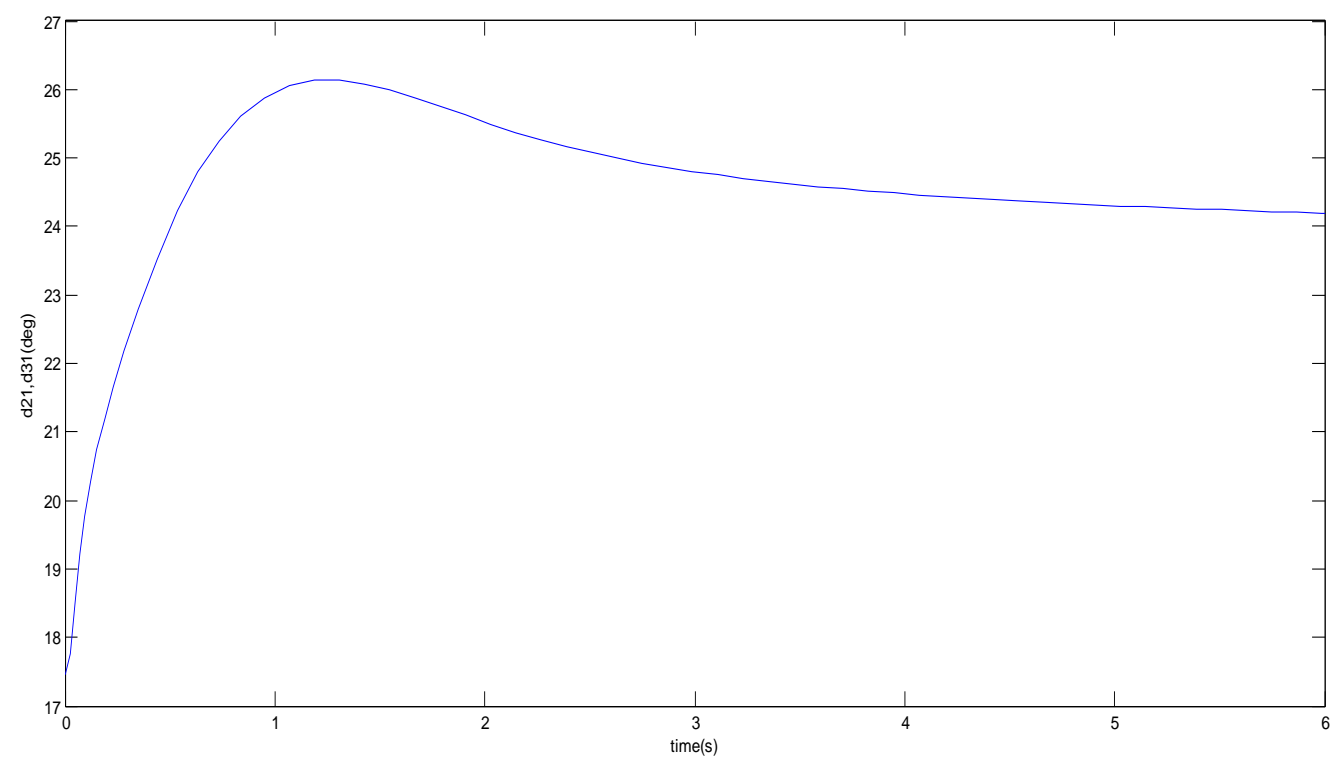

From the above Figure, it is observed that the oscillations in rotor angle are completely damped. Also, the desired transient response can be obtained by suitably changing the parameters using the Simulink setup of fig 4 . The stability of the system with fault can also be improved by merely changing the parameters.

\section{CONCLUSION}

In this paper, the advantages of using SSSC controller for obtaining sufficient damping of oscillations for WSCC 3 Machine 9 Bus system under fault conditions have been clearly demonstrated with the help of the developed SIMULINK setups and the graphs. These setups are very general and easy for implementation and desired time responses can be quickly and accurately obtained. Also, any SMIB and MultiMachine systems can be analyzed getting the indicated advantages.

\section{ACKNOWLEDEMENT}

The authors wish to thank the management of CVR College of Engineering for their encouragement in the completion of this work.

\section{REFERENCES}

[1] Ramnarayan Patel, T.S.Bhatti and D.P.Kothari, Matlab/Simulink -based Transient Stability analysis of a multimachine power system, International journal of Electrical Engineering Education 39/4.

[2] M.H. Haque, Damping improvement by FACTS devices: A comparison between STATCOM and SSSC,Electric Power System Research, Vol.76,2006, pp. 865-872.

[3] Amara SAIDI,Hsan HADJ ABDALLAH, Improvement of Transient Stability by FACTS devices,ICGST-ACSE Journal,Vol 11 ,issue 1,June 2011.

[4] Hadi Saadat, Power System analysis (McGraw-Hill, New York, 1999.)

[5] R. Ramanujam, Power System DynamicsAnalysis and Simulation, PHI Learning Pvt Ltd, 2009.

[6] P.M. Anderson and A.A. Fouad, Power system Control and Stability.

[7] P.Kundur, Power System Stability and Control, EPRI Power System Engineering Series (Mc.Graw -Hill, New York, 1994).

[8] Simulink User's Guide (The Mathworks, Natick, MA.1999). 